This vivid and well researched book by Dianna Melrose from Oxfam details the paradoxes which attend the business of medicine when it is detached from charity or caring. When the medical enterprise is purely a matter of selling skills and medicaments 'caveat emptor' is the order of the day. In these circumstances some patients die of diseases for which there are no treatments. Some of the poorest, who can afford neither treatment nor drugs, die of diseases that are curable or preventable. And families may make immense sacrifices to purchase drugs which are unnecessary, while they go short of food. Drugs do have uses and are effective, both for the cure of some ills and for the alleviation of symptoms. But at present the rich are more likely to enjoy superior health and to receive more suitable medication than the poor.

Awareness of the issue is promoted by the World Health Organisation, with its recent emphasis on primary health care. Manufacturers too are beginning to accept some responsibility to Third World countries through an international federation. There are also attempts, by some governments, to legislate on drug importation and distribution. Rich nations have taken at least one firm stand, in relation to limiting the sale of breast-milk substitutes.

Oxfam's final recommendations are all fine and good as far as they go. They are discreetly apolitical, aiming for agreements between decent gentlemen. But can we continue to ignore the politics of medicine?

UNA MACLEAN Head of Department of Community Medicine, Edinburgh University

\section{Blood: Gift or Merchandise?}

Piet J Hagen, New York, Alan R Liss Inc, 1983. $£ 17.00$

In 1973, the first commercially prepared material derived from the blood of paid donors was purchased in the United Kingdom for the treatment of haemophiliacs. In the years that immediately followed, the concept of 'home therapy' for haemophiliacs was actively promoted in the United Kingdom by directors of the Haemophilia Centres and also by The Haemophilia Society, and was vigorously supported by the companies marketing commercial factor VIII. In consequence, although the output of therapeutic fac- tor VIII by the United Kingdom Transfusion Services increased from 11 million units per annum in 1971 to 27 million units per annum in 1981, the commercial contribution rose to 35 million units. As Piet Hagen points out in this fascinating, well informed and accurate book, the United Kingdom 'lost its lead'.

The book gives a detailed and informed account of the organisation of the transfusion services in the industrialised countries, and is thus a useful reference source for all interested parties. It also highlights the global problems resulting from the worldwide dependence on paid blood donors, and in particular from the development of private plasmapheresis centres. Although the author is careful not to condemn the principle of paying blood donors and the development of blood products by private enterprise, the consequences of past and present practices for both donors and patients are vividly portrayed.

The author also highlights the challenging ethical issues facing doctors who are employed by commercial plasmapheresis stations or who are contracted or sponsored by them or the manufacturers. Such doctors face a complex conflict of loyalties. Firstly they are responsible to the donors to ensure that they are healthy, and that their health is not impaired by repeated donation procedures. This may not be easy in situations where the donor (and sometimes family) become dependent on the supplementary income. Donors in such situations are more likely to be a source of 'substandard' blood (principally by the transmission of infectious agents presently undetectable) - hence there is a second responsibility to the ultimate recipient. Thirdly, the doctor is accountable to the processors for each rejected donor or donation as such rejections represent lost money.

The research into the book is thorough but unfortunately, although inevitably, stops at 1981 . This is a pity because two specific topics of current high interest are not mentioned; namely the consequences of pasteurisation of blood products, and the Acquired Immunodeficiency Syndrome (AIDS).

AIDS was first described in New York four years ago and is a chronic but often fatal disorder affecting previously healthy young homosexual men. It is now reaching epidemic proportions and its cause remains unknown, although it is thought to be an infective agent (or agents) transmitted by intimate contact, with an incubation time of many months. It is known to be transmissible in blood and blood products, and it is therefore of great concern to, for example, the haemophiliac community. To cast an 'ethical' interpretation on AIDS in recipients and see it as a consequence of commercialisation of blood collecting and processing services would, of course, be quite wrong. This is illustrated, for example, by pasteurisation, or similar processes, which have the potential of effectively destroying all infectious agents in blood for transfusion. When such processes are developed, it will no longer be valid to associate the use of non-remunerative, voluntarily (ie 'ethically') donated blood, with patient safety, as exploitation of unhealthy donors could be resumed or continued with no extra danger to the recipient. It is worth noting that for some time pasteurised albumin preparations of commercial origin have been available - indeed the United Kingdom is heavily dependent on these for the support of major clinical programmes such as cardiac surgery, renal dialysis and burns therapy - and also that techniques for pasteurisation of other blood products without excessive losses is at an advanced stage.

It is also worth recalling that most Services test each donation for the possible presence of syphilis by the VDRL test. It has long been recognised, particularly by genito-urinary specialists, that people may donate blood principally to obtain assurance (on the nonews-is-good-news principle) that they have a negative VDRL. This practice of blood transfusion services may therefore actually attract donations from the very communities at risk of harbouring AIDS and which in the interests of recipient safety should be avoided. This issue is one aspect of the responsibilities of which the donor communities need to be aware. It is not particularly emphasised in Mr Hagen's book, although to be fair until AIDS became recognised it was not easy to associate particular donor life-styles (as distinct from ill health) with risks to recipients.

No strong ethical stance is taken overtly at any rate - in this book, and this adds to its strength. Issues are indeed raised, and detailed discussion of the practices shows them in sharp relief, but the ethical conclusions are left to the reader. There are one or two minor deficiencies - such as unclear tables - and I would have expected more detailed discussion of the practice of boosting donors with human-derived materials, such as rhesus positive cells for the provision of anti-D in the prevention of haemolytic disease of the newborn. 
However, I recommend this book most highly for all interested in any aspect of blood supply, from donor to patient, including blood bankers, haematologists, surgeons and patient consumer societies; as well as politicians and economists. Mr Hagen is to be congratulated.

DR F E BOULTON

Deputy Director, Edinburgh E South-East Scotland Blood Transfusion Service, Royal Infirmary of Edinburgh.

\section{Medical Genetics Casebook}

Colleen D Clements, Clifton, New Jersey, The Humana Press Inc, 1982. $\$ 29.50$

Medical ethics is an emergent specialty, and the author believes that, like many people in the youthful phase of life, it is suffering from an identity crisis. It does not know of which parent it is the offspring - medicine? ethics? philosophy? It is uncertain of its real function - who it is addressing, who it is protecting, and it does not even know what questions it really should be asking. In this book, the author seeks to take this young upstart by the scruff of the neck and give it a meaning and purpose in life.

The root of the identity problem seems to lie in the enormous gulf which exists between theory and practice, between the armchair ethicist and the clinician. While both disciplines need to change their attitudes and conceptual frameworks, the author lays the bulk of the blame at the feet of the 'theoretician', who is particularly inflexible. $\mathrm{He}$ uses pre-existing structures and theories to meet the new situations with which he is confronted, and since these are static, they do not give any opportunity for change and growth. The author, a philosopher, has, for a prolonged period, been actively involved in the day-to-day workings of a medical genetics unit, and has observed how medicine, because it is clinical, is a 'self corrective process' and continuously changes to adapt itself to new situations. She has recognised the value of this to ethics so she has tried to apply it to this subject.

She describes cases from the medical genetics clinic (130 in all), then identifies the ethical issues, and finally uses systems theory to clarify the problems presented by the cases. This approach, starting with a clinical perspective and proceeding to the theoretical, is the opposite of that usually taken by ethicists.

The first chapter introduces some important areas - attitudes to pain and suffering, the use and abuse of information, the right use of scarce medical resources, undesirable side-effects of treatment, which are not, of course, unique to medical genetics. The next five chapters are much more specific, and are largely related to pre-natal diag; nosis. The worth of the individual, selective abortion, societal versus individual interests, perceptions of risk and the use of experimental and research procedures are amongst those considered. The final chapter elaborates the concepts and summarises the new approach to medical genetics which has been proposed and developed throughout the book.

Philosophy is a difficult subject for the outsider to grasp. The systems theory, which is the key to the study, for it is that which permits the introduction of the aspired-to flexibility, is explained ‘. . [it] attempts to remain in a controlled state, which involves mechanisms for maintaining swings and oscillations within certain limits sufficient to prevent such wild gyrations that the whole system breaks down. This is accomplished by feedback loops . . . . Later, when examining spontaneous abortion, killing is described as 'disrupting a homeostatic system composed of biotic material capable of being partially described on a reductive biochemical/ biophysical level'. If these sentences are your delight, then this book is for you. However, as a non-expert, I found page after page of such verbiage hard to take. I suspect this book will do better on the American market than in the UK, for Americans seem so attuned to this verbosity and jargon.

I cannot agree with the inscription on the flyleaf of the book 'that it will be of immense practical utility to the physician', but this is not to say physicians shouldn't read it. On the other hand, philosophers and ethicists will surely relish the intellectual challenge of this new working model for medical ethics, and medical students, if they are selective, could extract from it information on the wide range of medical problems encountered by a medical genetics unit and some of the more immediate ethical ramifications.

MARY J SELLER Paediatric Research Unit, The Prince Philip

Research Laboratories, Guy's Hospital Medical School, London
News and notes

\section{Money, justice and medical care}

Professor Bernard Williams will give the John Locke lecture at the Society of Apothecaries, Blackfriars Lane, London EC4 on Tuesday January 24 at $6 \mathrm{pm}$. The title will be: Money, justice and medical care. 